\title{
How I Do It? Endoscopic Modified Inlay Butterfly Cartilage Perichondrium Myringoplasty
}

\section{Shrestha BL}

Department of ENT-HNS, Dhulikhel Hospital

Kathmandu University Hospital, Dhulikhel , Kavre, Nepal

\section{INTRODUCTION}

Though the microscope has helped a lot in otological surgical procedure but it has same optical properties for the last three decades. ${ }^{1}$ Thus, it has its own limitation as it provides a magnified image along a straight line (Fig 1). ${ }^{2}$ Meanwhile, the introduction of endoscope in other area of medical field also finds its role in ear surgery. Since, the endoscopes have better optics and magnification with wide angle of view (Fig 2) due to angled lenses and provide the excellent resolution of image. This advantageous factor increases its role in surgeries having many difficult anatomic nooks and corners. ${ }^{3}$ The diagnostic and teaching role of endoscope in otological practice has already been proved. Apart from that, there are lots of other advantages of endoscope in otological surgeries like; antero-inferior recess of external auditory canal, middle ear cavity and difficult areas to visualize under microspore like sinus tympani can be well visualized. ${ }^{4,5}$

Since the perforation of tympanic membrane adversely affects the hearing and also causes the recurrent infection, so there are various grafts and techniques have been used to repair the tympanic membrane.

The various graft materials are skin, vein, perichondrium, temporalis fascia, dura and cartilage. ${ }^{6-15}$ The cartilage has been used in cases of negative prognostic factors like total or sub total perforation, anterior perforations, revision procedures, surgery in wet ear, extensive tympanosclerosis and pediatric age group. ${ }^{16}$ The main advantage of cartilage is that it has very low metabolic rate, provide support to prevent retraction, reacts minimally to inflammatory reaction. ${ }^{17}$

Eavey was the first to repair the small tympanic membrane perforation with cartilage graft butterfly myringoplasty and Rourke $\mathrm{T}$ et al followed the similar technique to close the perforation. ${ }^{18,19}$ Since, there is still the scarcity of study doing cartilage myringoplasty using the endoscope. So, we performed the cartilage myringoplasty (modified inlay butterfly perichondrium) with the rigid endoscope. For this, we had followed the similar technique like performed by Rourke $\mathrm{T}$ et al but with our own modification. ${ }^{19}$

\section{Patient selection and preoperative preparation}

The patient with age of $\geq 13$ years, both gender, and Chronic otitis media (mucosal- inactive) with central perforation of $>50 \%$ and those requiring revision surgeries for failed myringoplasty were included for surgery.

\section{Patient pre-operative preparation}

The patient was given oral ciprofloxacin 500milligram 12 hourly one day prior surgery and continued till 10th postoperative day. Since the surgery was performed under local anesthesia, so the patient was sedated with pethidine and promethazine intramuscularly as per body weight.

\section{Surgical procedure}

The patient was given $5-10 \mathrm{ml}$ of two percent xylocaine with 1:1,00,000 adrenalin as per the approach selected, for four quadrant canal wall block and also on tragus. About $2 \mathrm{~cm}$ vertical incision was given by number 15 scalpel from incisura terminalis upto intratragal notch which was around $5 \mathrm{~mm}$ medial to the tip of the tragus as shown in fig 3 . The single stroke skin incision was given upto tragus cartilage. The assistant held the tissue of the tip of the tragus by non tooth forceps and cleared the surgical field from blood by suction. Whereas the operating surgeon held the skin with non tooth forceps and then the canal side cartilage along with perichondrium was dissected with mosquito forceps as shown in fig 4. Similarly, cartilage along with perichondrium from the anterior aspect of tragal cartilage was dissected and thus made free at incisura terminalis.

The cartilage along with the perichondrium was excised with number 15 scalpel giving incision from incisura terminalis once the cartilage size of $2 \mathrm{~cm}$ in length and $1.5 \mathrm{~cm}$ in breadth was obtained. Thus, the cartilage was harvested. The skin was closed with 4/0 prolene interrupted suture.

Then, the graft was kept on silastic block. The perichondrium away from canal was elevated with number 15 scalpel and removed. For creating the butterfly, number 11 scalpel was used and thus created around $1.5 \mathrm{~mm}$ groove along the circumferential border of the cartilage disc allowing the cartilage flanges to spring open like did by Rourke T et al. ${ }^{14}$ If the handle of malleus and/or the incudostapedial joint was visible then we removed the cartilage partly to allow place for handle of malleus and incudostapedial joint.

\section{Use of Endosocope}

The rigid Hopkins II endoscope (Karl Storz) 0 degree and 30 degree with 4 millimeter diameter and 18 centimeter in length was passed through transcanal route to observe and assess the perforation, ossicular chain status, middle ear mucosa and also the eustachian tube orifice. Then, the margin of the perforation was refreshened with the 


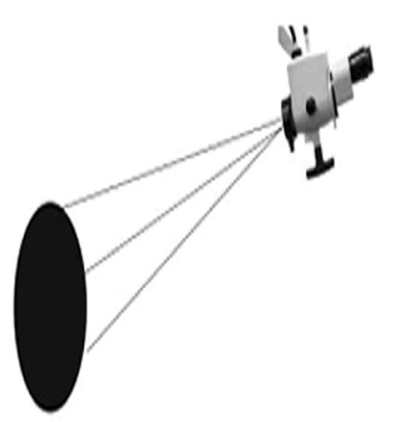

Figure 1. Magnified image along straight line of microscope.

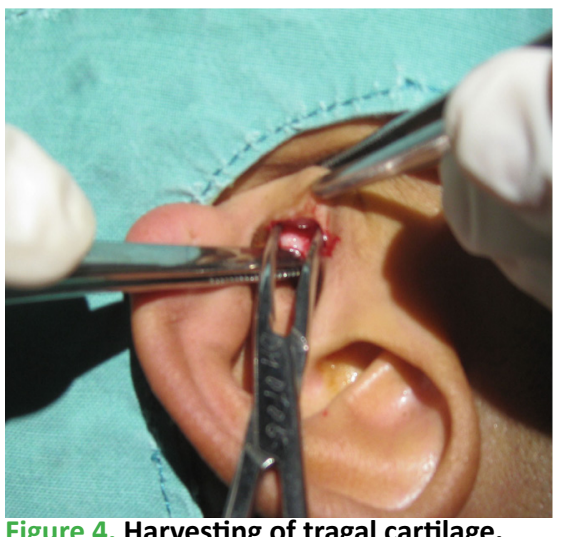

Figure 4. Harvesting of tragal cartilage.

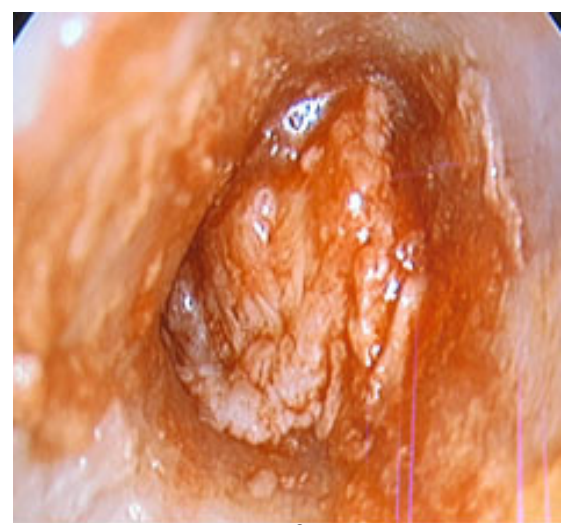

Figure 7. Placement of tragal cartilage

in remnant of tympanic membrane.

straight needle (Fig 5) and also the epithelial layer of the tympanic membrane around $5 \mathrm{~mm}$ was elevated off the fibrous layer with round knife around the perforation as shown in fig 6. Whenever the handle of malleus was visible, it was well skeletonized (Fig 6).The gelatin sponge was kept in the middle ear cavity with crocodile forceps. The cartilage graft was then placed around the perforated tympanic membrane like placing a grommet by first inserting on the anterior end of perforation by mounting on the crocodile forceps. Then rest of the cartilage was placed with straight needle. The cartilage rest in such a way that medial flange lies medial to tympanic membrane whereas the lateral flange containing the cartilage along endoscope.

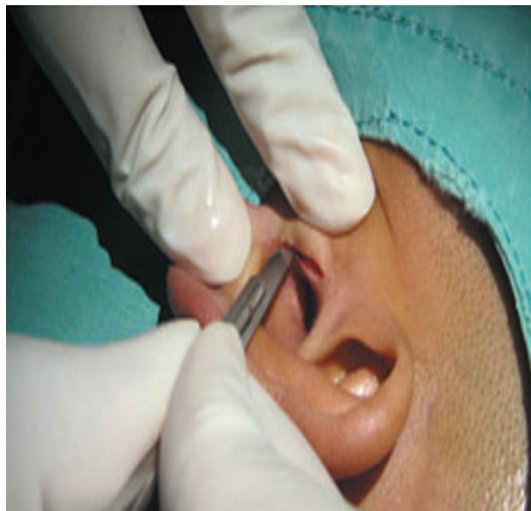

of Figure 3. Incision on tragus.

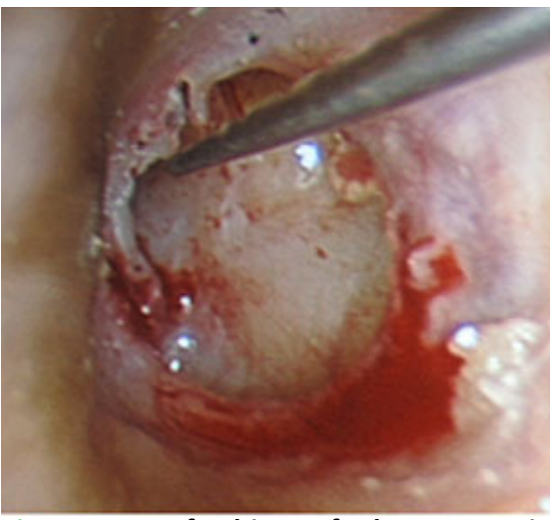

Figure 5. Refreshing of the tympanic membrane perforation margin.
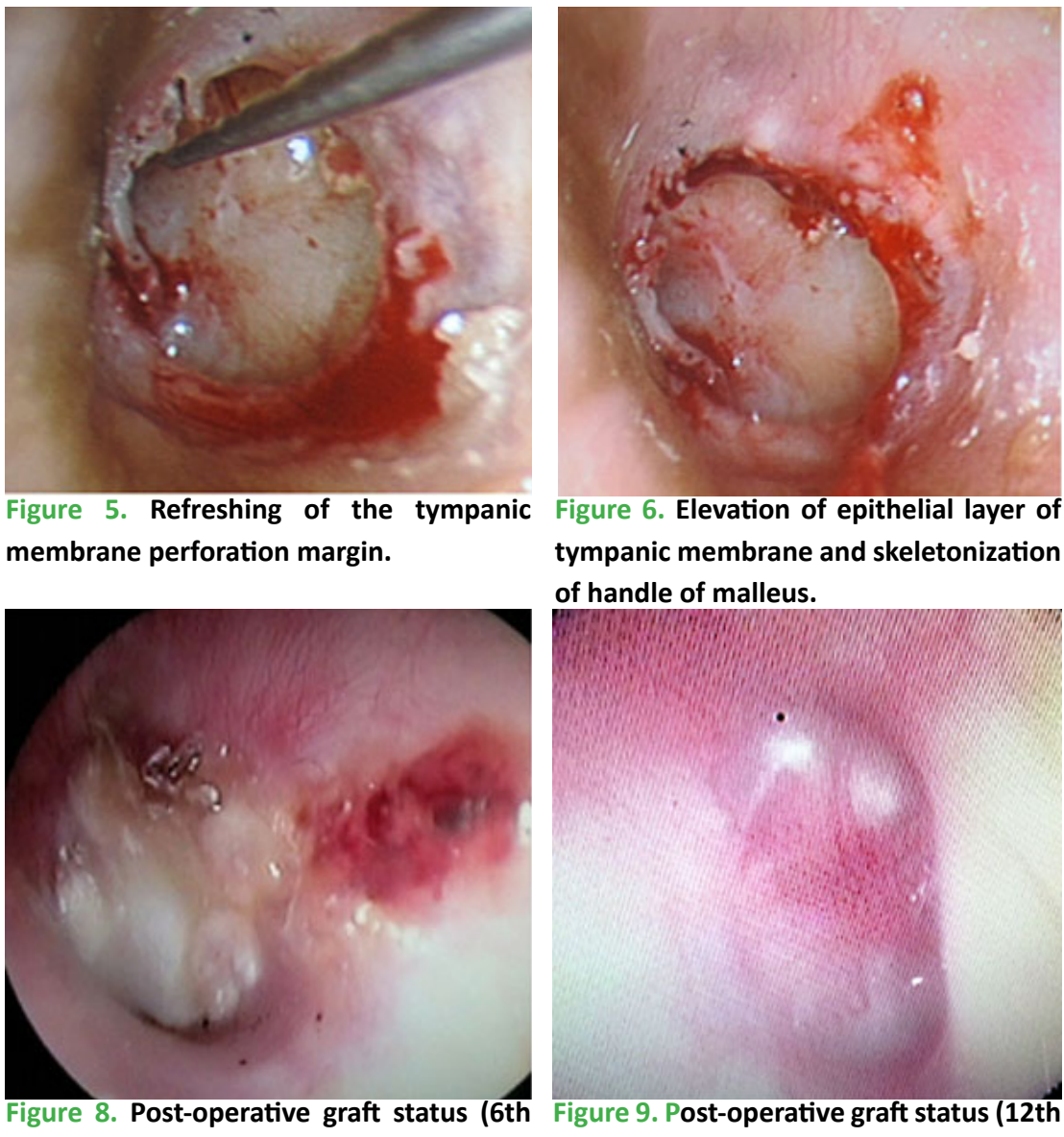

Figure 6. Elevation of epithelial layer of tympanic membrane and skeletonization of handle of malleus.

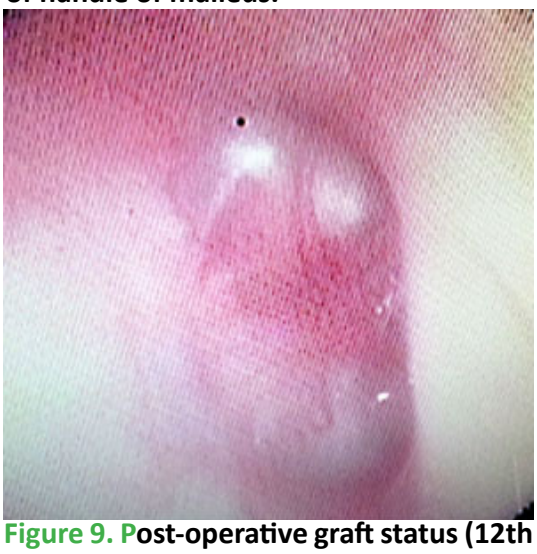

week).

with the perichondrium lies lateral to the perforation. The perichondrial end was then covered with rest of elevated epithelial layer of tympanic membrane as shown in fig 7. The canal was then packed with wet gelatin sponge soaked in ciprofloxacin ear drops and followed by the ribbon pack medicated with soframycin was kept in the canal and mastoid bandage was applied.

\section{Post-operative care and follow up}

The patient was prescribed tab ciprofloxacin 500mg 12 hourly for ten days. The ribbon gauge pack and the stitch was removed on $7^{\text {th }}$ postoperative day. The remaining gelatin sponge was suctioned on the same $7^{\text {th }}$ postoperative 
day. Then, the patient was prescribed chloramphenicol and dexamethasone ear drops for six weeks. The patient was again followed up after two weeks, six weeks (Fig 8) and 12 weeks (Fig 9). The hearing was assessed on 12 weeks.

\section{Audiological evaluation}

For the hearing assessment, pure tone audiogram was done seven days prior to operation and then 12 weeks after the operation. The audiological results were reported according to American Academy of Otolaryngology- Head and Neck Surgery guidelines. ${ }^{20}$

\section{RESULTS}

This study is going in the department of Otorhinolaryngology and head and neck surgery of Kathmandu University Hospital, Dhulikhel, Kavre. Till now, we have done 12 cases by endoscopic transcanal approach. The preliminary anatomic as well as functional results however are encouraging but the results are still to be published.

\section{REFERENCES}

1. Harugop AS, Mudhol RS, Godhi RA. A comparative study of endoscope assisted myringoplasty and microscope assisted myringoplasty. Indian J Otolaryngol head neck Surg 2008;60:299-302.

2. Yadav SP, Aggarwal N, Julaha M, Goel A. Endoscope-assisted myringoplasty. Singapore Medical Journal 2009;50(5):510-12.

3. Mattox DE. Endosocope-Assisted Surgery of the petrous Apex. Otolaryngol Head Neck Surg 2004;130:229-241.

4. Patil RN. Endoscopic tympanoplasty - Definitely advantageous (preliminary reports). Asian J Ear Nose Throat 2003;25:9-13.

5. Khan I, Jan AM, Shahzad F. Middle ear reconstruction: a review of 150 cases. J Laryngol Otol 2002; 116: 435-9.

6. Berthold E. Uber Myringoplastic. Med-chir centralb 1879;14:195-207.

7. Tabb HG. Closure of perforations of the tympanic membrane by vein grafts: a preliminary report of 20cases. Laryngoscope 1960;70:271286.

8. Goodhill V. Articulated polyethylene prosthesis with perichondrial graft in stapedectomy. Rev Laryngol (Bordeaux) 1951;82:305-320.

9. Linde RE. The cartilage-perichondrium graft in the treatment of posterior tympanic membrane retraction pockets. Laryngoscope 1973;83:747-53.

10. Storrs L. Myringoplasty with the use of Fascia Grafts. Arch Otolaryngol 1961;74:45-49.

11. Yetiser S, Tosun F, Satar B. Revision myringoplasty with solventdehydrated human dura mater. Otolaryngol Head Neck Surg 2001 May;124(5):518-21.

12. Heermann J, Heermann H, Kopstein E. Fascia and cartilage palisade tympanoplasty. Arch Otolaryngol 1970;91:228-41.

13. Couloigner V, Baculard F, El Bakkouri W, Viala P, Francois M, Narcy P et al. Inlay butterfly cartilage tympanoplasty in children. Otol Neurotol 2005;26:247-51.

14. Gerber MJ, Mason JC, Lambert PR. Hearing results after primary cartilage tympanoplasty. Laryngoscope 2000;110: 1994-912.

15. Adkins WY. Composite autograft for tympanoplasty and tympanomastoid surgery. Laryngoscope 1990;100:244-7.

16. Uslu C, Tek A, Tatlipinar A, Kilicarslan Y, Durmus R, Ayogredik E et al. Cartilage reinforcement tympanoplasty: ontological and audiological results. Acta Oto-Laryngol 2010;130:375-83.

17. Yung M. Cartilage tympanoplasty: literature review. J Laryngol Otol 2008; 122: 663-672.

18. Eavey RD. Inlay tympanoplasty: cartilage butterfly technique. Laryngoscope 1998;108:657-61

19. Rourke T, Snelling JD, Aldren C. Cartilage graft myringoplasty: how we do it. Clinical Otolaryngology 2010;35:135-146.

20. American Academy of Otolaryngology-Head Neck Surgery Foundation, Inc. Committee on Hearing and Equilibrium guidelines for the evaluation of results of treatment of conductive hearing loss. Otolaryngol Head Neck Surg 1995;113:186-7. 